\title{
MATRIK
}

Jurnal Manajemen dan Teknik Industri-Produksi

Journal homepage: http://www.journal.umg.ac.id/index.php/matriks

\section{Perencanaan Produksi Dengan Metode Goal Programming Pada UKM XYZ}

\section{Dimas Krissyda $^{1^{*}}$, Teguh Oktiarso ${ }^{2}$}

Program Studi Teknik Industri, Fakultas Sains dan Teknologi, Universitas Ma Chung Jl. Villa Puncak Tidar N-01, Malang, Jawa Timur, Indonesia teguh.oktiarso@machung.ac.id

\section{INFO ARTIKEL}

\section{Jejak Artikel :}

Upload artikel

20 Juli 2020

Revisi

O2 September 2021

Publish

30 September 2021

\section{Kata Kunci :}

Goal Programming, Rencana

Produksi, Nilai Pengendapan

Produk Rata-rata

\section{ABSTRAK}

UKM XYZ merupakan produsen empat belas jenis sambungan pipa dan satu jenis karet paku. Perusahaan mengalami kondisi overstock dan out-of-stock secara terus menerus karena perencanaan produksi yang kurang sesuai. Diusulkan sebuah rencana produksi menggunakan metode goal programming untuk memenuhi tujuan perusahaan yaitu memenuhi permintaan dan minimasi stok. Data permintaan historis akan digunakan sebagai data masukan pada model dan diolah dengan tiga metode peramalan deret waktu. Program LINGO 16.0 akan digunakan untuk perhitungan model rencana produksi. Hasil model pertama tidak dapat memenuhi permintaan dan memiliki nilai pengendapan stok produk ratarata $\mathrm{Rp}$ 498.125,00 lebih banyak dari rencana UKM XYZ, maka diusulkan dua model perbaikan. Model kedua akan menggunakan pembobotan kuadrat dan model ketiga akan menggunakan variabel pemenuhan permintaan pada dua periode di masa depan. Hasil perhitungan menunjukkan bahwa kedua model dapat memenuhi permintaan. Nilai pengendapan produk rata-rata dengan model kedua adalah Rp 678.333,00 lebih sedikit dari rencana UKM XYZ, sedangkan nilai pengendapan produk rata-rata model ketiga adalah $\mathrm{Rp}$ 303.542,00 lebih sedikit dari rencana UKM XYZ. Kedua model dapat memenuhi tujuan perusahaan dengan model kedua sebagai usulan terbaik. 


\section{Pendahuluan}

UKM XYZ merupakan perusahaan make-tostock yang memproduksi empat belas jenis sambungan pipa dan satu jenis karet paku. Perusahaan ini sering mengalami overstock dan out-of-stock pada produknya. Hal ini menunjukkan kondisi produksi dan persediaan yang kurang efisien. Diperlukan suatu rencana perbaikan yang dapat membantu memperbaiki kondisi perusahaan ini [1].

Masalah penjadwalan produksi sederhana dapat diselesaikan dengan metode program linear, namun metode ini tidak dapat menghitung penjadwalan dengan beberapa tujuan. Disamping itu, UKM XYZ menetapkan tujuannya untuk memenuhi permintaan dan minimasi stok. Maka, akan digunakan metode goal programming yang dapat memenuhi beberapa tujuan secara bersamaan. Metode ini merupakan pengembangan dari metode program linear.

Tujuan dari penelitian ini adalah membuat peramalan permintaan yang dapat digunakan untuk membantu penjadwalan produksi, membuat jadwal produksi optimal, dan merencanakan pengendalian persediaan dengan memanfaatkan penjadwalan produksi.

\section{Metode Penelitian}

Peramalan permintaan akan menggunakan peramalan deret waktu dengan menggunakan tiga metode. Ketiga metode tersebut adalah horizontal moving average forecasts, horizontal (exponentially) smoothing forecasts, dan linear trend line [2]. Pemilihan penggunaan metode pada setiap data produk akan didasarkan pada tingkat akurasi peramalan yang digunakan [3],[4]. Nilai akurasi peramalan akan dihitung menggunakan mean absolute deviation (MAD). Semakin kecil nilai MAD, maka data hasil peramalan akan semakin mendekati nilai permintaan aktualnya [5],[6].

Penggunaan metode integer linier programming untuk penjadwalan produksi multi product telah dilakukan dengan bantuan Lingo 16. Hasil dari penggunaan metode ini adalah minimasi total tardiness untuk produksi empat jenis produk container dibandingkan dengan metode FCFS.[7]

Goal Programming memodelkan penjadwalan produksi pakaian sesuai dengan tren yang sedang berlangsung [8]. Hasil dari penjadwalan adalah income, coat dan utilisasi mesin yang meningkat sesuai dengan tren yang berlangsung.

Metode linear programming merupakan teknik permodelan matematis yang digunakan untuk menentukan tingkatan aktivitas operasional untuk mencapai satu fungsi tujuan dengan batasan-batasan tertentu. Batasan yang digunakan dapat berupa keterbatasan waktu, tenaga kerja, energi, bahan baku, atau uang. Metode ini digunakan banyak digunakan untuk memaksimalkan keuntungan atau meminimalkan biaya. Metode ini menggunakan rumus [4]:

Maksimasi (atau minimasi) $Z=c_{1} x_{1}+$ $c_{2} x_{2}+\cdots+c_{n} x_{n}$

Dengan batasan:

$a_{n 1} x_{1}+a_{n 2} x_{2}+\cdots+a_{n n} x_{n}(\leq,=, \geq) b_{n}$

(2)

$x_{i} \geq 0$

Keterangan:

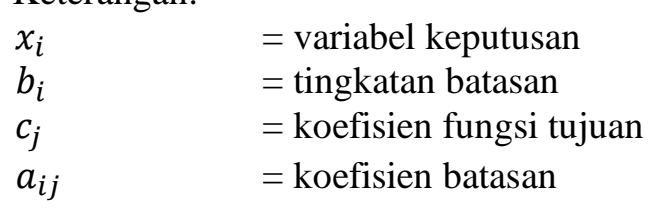

Penelitian akan diawali dengan melakukan observasi pada perusahaan untuk melihat kondisi awal dari bisnis yang dijalankan. Identifikasi masalah akan dilakukan berdasarkan data kasar yang didapat saat melakukan observasi. Masalah akan dirumuskan berdasarkan hasil identifikasi dan tujuan penelitian akan didasarkan pada perumusan masalah.

Berdasarkan masalah yang dihadapi, langkah pertama dalam sebuah perencanaan produksi yaitu peramalan permintaan akan dilakukan terhadap data historis permintaan pada lima belas jenis produk. Data historis yang digunakan adalah data permintaan mingguan dari Oktober 2016 (periode 1) hingga data pada akhir Februari 2017 (periode 22). Hasil dari peramalan permintaan akan digunakan sebagai dasar pemenuhan permintaan pada model.

LINGO versi 16 merupakan software matematika yang cukup lengkap dalam perancangan model linear programming. Pada perencanaan model untuk Goal Programming, multi kriteria tujuan dari model dapat disertakan sehingga solusi dari software adalah optimasi dari model tersebut. [9] Pemodelan untuk penjadwalan produksi yang menggunakan 
linear programming akan terbantu dengan membuat model yang lebih kompleks seperti fuzzy goal programming dengan beberapa multi kriteria utntuk meminimalkan biaya, memaksimalkan utilisasi mesin serta meminimalkan kejadian backorder [10][11][12].

Pembuatan model goal programming akan dilakukan dengan menggunakan model matematika. Perhitungan model akan dilakukan dengan program LINGO 16.0 dengan penyesuaian model [13][14][15]. Program LINGO 16.0 akan menghasilkan data penjadwalan produksi dari model. Data ini akan diolah untuk mendapatkan data persediaan di setiap akhir periode. Data persediaan ini akan digunakan untuk menghitung nilai pengendapan barang pada gudang. Data hasil model akan dianalisis dan dibandingkan dengan data hasil perencanaan UKM XYZ. Hasil analisis dari hasil perencanaan produksi dengan menggunakan goal programming akan digunakan untuk menunjukkan apakah perencanaan produksi dengan menggunakan goal programming lebih baik dibandingkan dengan perencanaan produksi yang selama ini digunakan oleh UKM XYZ.

\section{Hasil dan Pembahasan}

\subsection{Peramalan Permintaan}

Peramalan permintaan akan dilakukan dengan menggunakan data permintaan historis dari lima belas jenis produk sejak Oktober 2016 (periode 1) hingga Februari 2017 (periode 22). Data ini akan digunakan untuk peramalan permintaan periode 23 hingga periode 28 . Berikut merupakan tabel pemilihan metode pada setiap jenis produk:

Tabel 1. Metode Peramalan 15 Produk

\begin{tabular}{|c|c|c|}
\hline $\begin{array}{l}\text { Produk } \\
\text { Mesin } 1 \\
\end{array}$ & Metode & MAD \\
\hline $\mathrm{K} 4$ & $\begin{array}{c}\text { Moving Average } 9 \\
\text { Periode } \\
\end{array}$ & 149,57 \\
\hline S4 & Regresi Linear & 80,87 \\
\hline T3 & $\begin{array}{c}\text { Moving Average } 5 \\
\text { Periode }\end{array}$ & 86,41 \\
\hline $\begin{array}{l}\text { Produk } \\
\text { Mesin } 2\end{array}$ & Metode & MAD \\
\hline K3 & Regresi Linear & 346,75 \\
\hline $\mathrm{K} 2,5$ & Regresi Linear & 151,87 \\
\hline S3 & $\begin{array}{c}\text { Moving Average } 4 \\
\text { Periode }\end{array}$ & 94,00 \\
\hline
\end{tabular}

\begin{tabular}{ccc}
\hline T2,5 & Regresi Linear & 60,07 \\
\hline ST & $\begin{array}{c}\text { Moving Average 6 } \\
\text { Periode }\end{array}$ & 58,85 \\
\hline $\begin{array}{c}\text { Produk } \\
\text { Mesin 3 }\end{array}$ & Metode & MAD \\
\hline K2 & Regresi Linear & 183,98 \\
\hline S2,5 & Horizontal Smoothing & 66,04 \\
\hline S2 & Moving Average 10 \\
Periode & 57,25 \\
\hline T2 & Moving Average 10 \\
\hline P1,5 & Regriode & 43,00 \\
\hline TT & Regresi Linear & 33,51 \\
\hline KP & Horizontal Smoothing & 813,62 \\
\hline
\end{tabular}

Terdapat tiga buah mesin untuk memproduksi lima belas jenis produk tersebut. Ketiga mesin merupakan mesin kapasitas besar, mesin kapasitas menengah, dan mesin kapasitas kecil. Setiap data produk telah diolah menggunakan tiga jenis metode peramalan dan dipilih peramalan dengan nilai MAD terkecil. Hasil peramalan permintaan akan digunakan sebagai variabel dalam perhitungan perencanaan produksi dengan metode goal programming.

\subsection{Permodelan Matematika Pertama}

Permodelan Matematika akan dibuat untuk setiap periode dan akan diulang proses permodelannya untuk menghasilkan model pada periode berikutnya. Model akan menggunakan data kapasitas produksi per hari, data jumlah stok awal, data peramalan permintaan, data kapasitas produksi, dan data kapasitas waktu produksi. Berikut merupakan keterangan model yang akan digunakan:

Tabel 2. Keterangan Model Matematika

\begin{tabular}{|c|c|c|c|}
\hline $\begin{array}{l}\text { Variabel } \\
\text { Dasar }\end{array}$ & Keterangan & $\begin{array}{l}\text { Variabel } \\
\text { Dasar }\end{array}$ & Keterangan \\
\hline A & Jumlah stok awal & Y2 & $\begin{array}{l}\text { Mesin } 2 \\
\text { (Y) produk } \\
\text { K2,5 }\end{array}$ \\
\hline $\mathrm{D}$ & Jumlah peramalan permintaan & Y3 & $\begin{array}{l}\text { Mesin } 2 \\
\text { (Y) produk } \\
\text { S3 }\end{array}$ \\
\hline $\mathrm{C}$ & Kapasitas produksi (buah) & $\mathrm{Y} 4$ & $\begin{array}{l}\text { Mesin } 2 \\
\text { (Y) produk } \\
\text { T2,5 }\end{array}$ \\
\hline $\mathrm{T}$ & $\begin{array}{l}\text { Kapasitas waktu produksi } \\
\text { (hari) }\end{array}$ & Y5 & $\begin{array}{l}\text { Mesin } 2 \\
\text { (Y) produk } \\
\text { ST }\end{array}$ \\
\hline $\mathrm{R}$ & Jumlah rencana produksi & $\mathrm{Z1}$ & $\begin{array}{l}\text { Mesin } 3 \\
\text { (Z) produk } \\
\text { K2 }\end{array}$ \\
\hline K & Jumlah stok akhir & $\mathrm{Z} 2$ & $\begin{array}{l}\text { Mesin } 3 \\
\text { (Z) produk } \\
\text { S2,5 }\end{array}$ \\
\hline
\end{tabular}




\begin{tabular}{clcl}
\hline $\mathrm{P}$ & $\begin{array}{l}\text { Jumlah stok akhir lebih dari } \\
\text { nol }\end{array}$ & z3 & $\begin{array}{l}\text { Mesin 3 } \\
\text { (Z) produk } \\
\text { S2 }\end{array}$ \\
\hline $\mathrm{N}$ & $\begin{array}{l}\text { Jumlah stok akhir kurang dari } \\
\text { nol }\end{array}$ & z4 & $\begin{array}{l}\text { Mesin 3 } \\
\text { (Z) produk } \\
\text { T2 }\end{array}$ \\
\hline X1 & Mesin 1 (X) produk K4 & z5 & $\begin{array}{l}\text { Mesin 3 } \\
\text { (Z) produk } \\
\end{array}$ \\
& Mesin 1 (X) produk S4 & z6 & $\begin{array}{l}\text { Mesin 3 } \\
\text { (Z) produk } \\
\text { TT }\end{array}$ \\
\hline X2 & & $\begin{array}{l}\text { Mesin 3 } \\
\text { (Z) produk } \\
\text { KP }\end{array}$ \\
\hline X3 & Mesin 1 (X) produk T3 & z7 & \\
& & & \\
\hline Y1 & Mesin 2 (Y) produk K3 & & \\
\hline
\end{tabular}

Berikut merupakan model fungsi tujuannya:

Minimize $\left(P_{X 1}+N_{X 1}\right)+\left(P_{X 2}+N_{X 2}\right)+$ $\left(P_{X 3}+N_{X 3}\right)+\left(P_{Y 1}+N_{Y 1}\right)+\left(P_{Y 2}+N_{Y 2}\right)+$ $\left(P_{Y 3}+N_{Y 3}\right)+\left(P_{Y 4}+N_{Y 4}\right)+\left(P_{Y 5}+\right.$ $\left.N_{Y 5}\right)+\left(P_{Z 1}+N_{Z 1}\right)+\left(P_{Z 2}+N_{Z 2}\right)+$ $\left(P_{Z 3}+N_{Z 3}\right)+$ $\left(P_{Z 4}+N_{Z 4}\right)+\left(P_{Z 5}+N_{Z 5}\right)+\left(P_{Z 6}+\right.$ $\left.N_{Z 6}\right)+\left(P_{Z 7}+N_{Z 7}\right)$

Berikut merupakan model batasan waktu dan mesin:

$T_{X 1}+T_{X 2}+T_{X 3} \leq 6$

$T_{Y 1}+T_{Y 2}+T_{Y 3}+T_{Y 4}+T_{Y 5} \leq 6(10)$

$T_{Z 1}+T_{Z 2}+T_{Z 3}+T_{Z 4}+T_{Z 5}+T_{Z 6}+T_{Z 7} \leq 6$

(11)

$T_{X 1}+T_{X 2}+T_{X 3}+T_{Y 1}+T_{Y 2}+T_{Y 3}+T_{Y 4}+$

$T_{Y 5}+T_{Z 1}+T_{Z 2}+T_{Z 3}+T_{Z 4}+T_{Z 5}+$

$T_{Z 6}+T_{Z 7} \leq 12$

Berikut merupakan model persamaan pertama untuk periode 23:

$$
\begin{aligned}
& 125 T_{X 1}-P_{X 1}+N_{X 1}=239 \\
& 125 T_{X 2}-P_{X 2}+N_{X 2}=-141 \quad(14) \\
& 225 T_{X 3}-P_{X 3}+N_{X 3}=162 \quad(15) \\
& 300 T_{Y 1}-P_{Y 1}+N_{Y 1}=177 \quad(16) \\
& 300 T_{Y 2}-P_{Y 2}+N_{Y 2}=-407 \quad(17) \\
& 300 T_{Y 3}-P_{Y 3}+N_{Y 3}=94 \quad(18) \\
& 250 T_{Y 4}-P_{Y 4}+N_{Y 4}=-315 \quad(19) \\
& 300 T_{Y 5}-P_{Y 5}+N_{Y 5}=-791(20) \\
& 450 T_{Z 1}-P_{Z 1}+N_{Z 1}=-419(21) \\
& 300 T_{Z 2}-P_{Z 2}+N_{Z 2}=-143(22) \\
& 450 T_{Z 3}-P_{Z 3}+N_{Z 3}=-947(23) \\
& 300 T_{Z 4}-P_{Z 4}+N_{Z 4}=-1074(24) \\
& 450 T_{Z 5}-P_{Z 5}+N_{Z 5}=-326(25)
\end{aligned}
$$

$$
\begin{aligned}
& 450 T_{Z 6}-P_{Z 6}+N_{Z 6}=-385(26) \\
& 1000 T_{Z 7}-P_{Z 7}+N_{Z 7}=1576(27)
\end{aligned}
$$

Persamaan tersebut didapatkan dengan melakukan subtitusi terhadap setiap variabel yang digunakan. Berikut merupakan rumus perhitungan jumlah rencana produksi:

$R_{X 1}=C_{X 1} \times T_{X 1}$

Berikut merupakan rumus jumlah stok akhir:

$K_{X 1}=A_{X 1}+R_{X 1}-D_{X 1}$

Berikut merupakan persamaan matematis goal programming dengan tujuan meminimalkan deviasi positif dan negatif dari persediaan akhir: $K_{X 1}-P_{X 1}+N_{X 1}=0$

\subsection{Permodelan LINGO Pertama}

Permodelan LINGO akan menggunakan logika model matematika sebelumnya dengan penyesuaian terhadap bahasa program LINGO 16.0. Berikut merupakan gambar dari model pertama periode 23 .

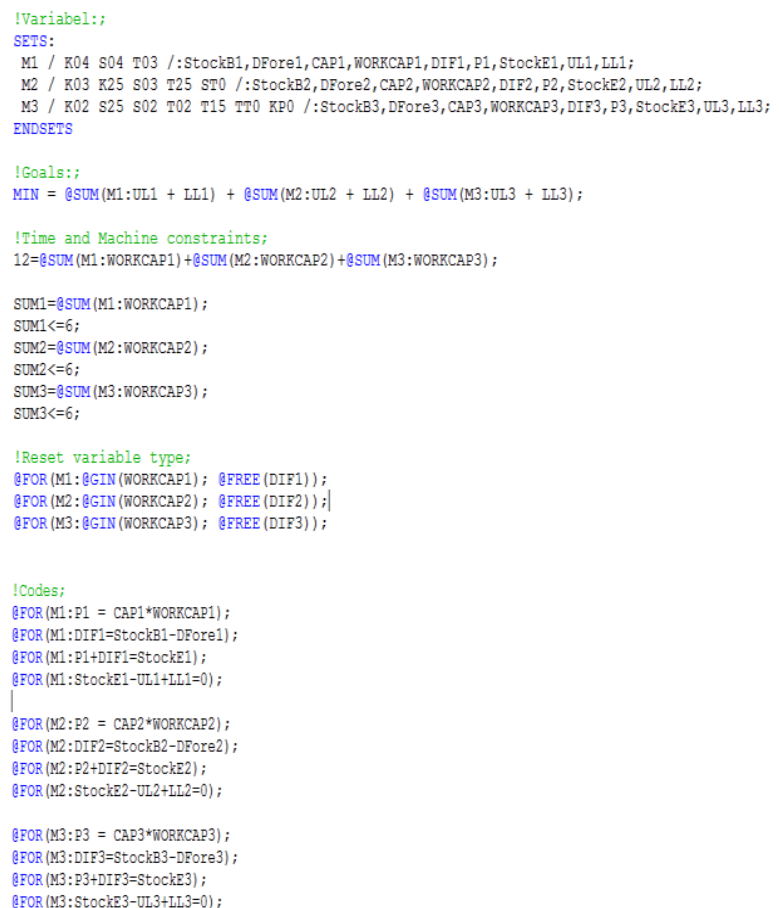

QFOR (N3:StockE3-UL3+LLI3=0) 


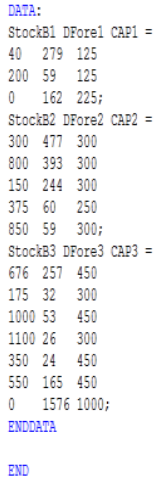

Gambar 1. Model Pertama Periode 23

\subsection{Hasil dan Analisis Model Pertama}

Model pertama akan menghasilkan jumlah produksi dari setiap produk berdasarkan prinsip goal programming. Jumlah produksi tersebut akan dikurangi dengan data permintaan nyata untuk mendapatkan jumlah persediaan akhir pada setiap periode. Berikut merupakan tabel perbandingan persediaan Model Pertama dengan UKM XYZ:

Tabel 3. Perbandingan Persediaan Model 1 dan UKM XYZ

\begin{tabular}{|c|c|c|c|c|c|c|c|c|c|c|c|c|c|c|c|c|}
\hline riode & & $\mathrm{K} 4$ & 54 & 13 & 3 & K2,5 & 99 & 125 & SI & & 52,5 & 52 & T2 & $\pi 1,5$ & TT & KP \\
\hline & & 90 & 250 & & 550 & 800 & 450 & 3758 & 85 & & 177 & 1000 & 1100 & 350 & 475 & \\
\hline & & no & 500 & 0 & & 800 & 450 & 8758 & 850 & & 176 & 1000 & 1100 & 350 & 476 & 2000 \\
\hline & & & 150 & 160 & 050 & 250 & 2050 & 3758 & 850 & & 176 & 1000 & 1100 & 350 & 1177 & \\
\hline & Model I & 90 & 1125 & 150 & $\sqrt{2}$ & 350 & 250 & 21258 & 850 & 376 & 177 & 1000 & 1100 & 350 & 275 & 2000 \\
\hline & & 135 & 1125 & 750 & 600 & 2200 & 2050 & 3757 & 780 & 176 & 177 & 1000 & 1100 & 350 & 1105 & \\
\hline & Model I & 260 & 1625 & 76 & 300 & 400 & 500 & 2875 & 780 & 76 & 176 & 1000 & 1100 & 350 & 2013 & 2000 \\
\hline & TWR & 735 & 1125 & 450 & 130 & 1400 & 1750 & 3006 & 680 & $M$ & 10 & $1 \mathrm{~m}$ & 1000 & 330 & 1105 & .2000 \\
\hline & & 110 & 2250 & 0 & 100 & .100 & 250 & 3550 & 680 & 176 & 10 & 1000 & 1000 & 330 & 205 & \\
\hline & & 810 & 1125 & 1575 & 050 & 1075 & 1750 & 3006 & 635 & 1001 & 610 & & 1000 & गJO & 930 & 000 \\
\hline & $\mathbb{1} 1 \mathrm{od}$ & 185 & 2500 & 220 & 2000 & 175 & 250 & 35506 & 665 & 501. & 310 & 1000 & 1000 & 350 & 30 & 1800 \\
\hline & & & 1125 & 1425 & 1050 & 975 & 1450 & 300 & 425 & $1 !$ & 400 & 800 & 1000 & 350 & 900 & 1800 \\
\hline & Model 1 & 235 & 3000 & 76 & .150 & 375 & .50 & 4050 & 428 & 251 & 160 & 800 & 1000 & 300 & 450 & \\
\hline
\end{tabular}

Berdasarkan nilai persediaan di atas, dapat diketahui bahwa terdapat beberapa nilai persediaan yang bernilai negatif, baik dari rencana UKM, maupun dari rencana model pertama. Hal ini menunjukkan bahwa perencanaan produksi dari UKM XYZ dan model pertama masih belum dapat memenuhi permintaan secara tepat. Hal ini dapat terjadi karena terdapat alokasi perencanaan produksi yang kurang sesuai dengan kondisi permintaan di masa depan. Berikut merupakan tabel perbandingan nilai pengendapan persediaannya:
Tabel 4. Perbandingan Nilai Pengendapan Persediaan Model 1 dan UKM XYZ (Rupiah)

\begin{tabular}{|c|c|c|c|c|c|c|c|}
\hline Periode & 23 & 24 & 25 & 26 & 27 & 28 & Ratar-yata \\
\hline UKXYXYZ & 24.568 .775 & 26.243 .775 & 33.955 .025 & 34.207 .275 & 40.809.150 & 41.267 .900 & 35.5060 .988 \\
\hline Model 1 & 24.088.775 & 28.141.275 & 348.815 .025 & 34.702 .275 & 40.544 .150 & 41.744 .150 & 34.005 .108 \\
\hline Selisih & 475.000 & .1897 .500 & & & & .476 .250 & .498 .125 \\
\hline
\end{tabular}

Hasil perbandingan di atas menunjukkan perencanaan model pertama memiliki nilai pengendapan persediaan rata-rata sebesar $\mathrm{Rp}$ 498.125,00 lebih besar dari rencana produksi UKM XYZ. Berdasarkan kemampuan pemenuhan permintaan dan besaran nilai pengendapan persediaan, maka hasil model pertama tidak lebih baik dari rencana UKM XYZ, maka akan dilakukan perbaikan terhadap model pertama.

\subsection{Perancangan Model Perbaikan}

Akan dibuat dua model perbaikan dengan tujuan utama agar model dapat memenuhi permintaan dengan baik. Kedua model akan menggunakan model pertama sebagai dasar logika. Model kedua menggunakan pembobotan kuadrat pada nilai deviasi positif persediaan akhir dengan tujuan membuat program memprioritaskan alokasi pada produk yang jumlah stoknya minimal. Model ketiga akan dibuat agar dapat memenuhi jumlah peramalan permintaan untuk dua periode di masa depan. Model ketiga dibuat dengan tujuan agar program dapat melakukan alokasi produksi pada produk yang cenderung akan habis terlebih dahulu pada 2 periode di masa depan.

\subsection{Perancangan Model Matematika Kedua}

Model matematika kedua memiliki rumus yang hampir sama dengan model pertama. Perbedaannya hanya terletak pada fungsi tujuan dengan memanfaatkan pembobotan kuadrat pada minimasi defiasi positif stok akhir. Berikut merupakan rumus tujuan model matematika kedua:

$$
\begin{aligned}
& \text { Minimize }\left(P_{X 1}{ }^{2}+N_{X 1}\right)+\left(P_{X 2}{ }^{2}+N_{X 2}\right)+ \\
& \left(P_{X 3}{ }^{2}+N_{X 3}\right)+\left(P_{Y 1}{ }^{2}+N_{Y 1}\right)+\left(P_{Y 2}{ }^{2}+\right. \\
& N_{Y 2}{ }^{2}+ \\
& \left(P_{Y 3}{ }^{2}+N_{Y 3}\right)+\left(P_{Y 4}{ }^{2}+N_{Y 4}\right)+\left(P_{Y 5}{ }^{2}+\right. \\
& \left.N_{Y 5}\right)+\quad\left(P_{Z 1}{ }^{2}+N_{Z 1}\right)+\left(P_{Z 2}{ }^{2}+N_{Z 2}\right)+ \\
& \left(P_{Z 3}{ }^{2}+N_{Z 3}\right)+\left(P_{Z 4}{ }^{2}+N_{Z 4}\right)+\left(P_{Z 5}{ }^{2}+\right. \\
& \left.N_{Z 5}\right)+\left(P_{Z 6}{ }^{2}+N_{Z 6}\right)+\left(P_{Z 7}{ }^{2}+N_{Z 7}\right)
\end{aligned}
$$




\subsection{Perancangan Model LINGO Kedua}

Model LINGO kedua akan mengikuti model pertama dengan perbedaan pada rumus tujuannya saja. Berikut merupakan gambar model tujuan LINGO kedua:

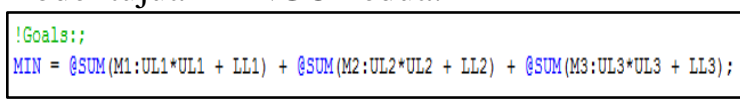

Gambar 2. Model Kedua Fungsi Tujuan

\subsection{Perancangan Model Matematika Ketiga}

Model matematika ketiga memiliki rumus yang hampir sama dengan model pertama. Perbedaannya terletak pada masukan nilai peramalan permintaan yang merupakan total permintaan dari dua periode di masa depan. Berikut merupakan model persamaan kedua pada periode 23:

$$
\begin{aligned}
& 125 T_{X 1}-P_{X 1}+N_{X 1}=496 \\
& 125 T_{X 2}-P_{X 2}+N_{X 2}=-84 \\
& 225 T_{X 3}-P_{X 3}+N_{X 3}=312 \\
& 300 T_{Y 1}-P_{Y 1}+N_{Y 1}=641 \\
& 300 T_{Y 2}-P_{Y 2}+N_{Y 2}=-3 \\
& 300 T_{Y 3}-P_{Y 3}+N_{Y 3}=338 \\
& 250 T_{Y 4}-P_{Y 4}+N_{Y 4}=-255(36) \\
& 300 T_{Y 5}-P_{Y 5}+N_{Y 5}=-741(39) \\
& 450 T_{Z 1}-P_{Z 1}+N_{Z 1}=-163(40) \\
& 300 T_{Z 2}-P_{Z 2}+N_{Z 2}=-111(41) \\
& 450 T_{Z 3}-P_{Z 3}+N_{Z 3}=-894(42) \\
& 300 T_{Z 4}-P_{Z 4}+N_{Z 4}=-1055(43) \\
& 450 T_{Z 5}-P_{Z 5}+N_{Z 5}=-303(44) \\
& 450 T_{Z 6}-P_{Z 6}+N_{Z 6}=-219(45) \\
& 1000 T_{Z 7}-P_{Z 7}+N_{Z 7}=2836(46)
\end{aligned}
$$

\subsection{Perancangan Model LINGO Ketiga}

Permodelan LINGO untuk model ketiga akan menggunakan beberapa variabel tambahan untuk menghitung permintaan pada dua periode di masa depan. Pada dasarnya, permodelan ini memiliki logika yang sama dengan model pertama. Perbedaannya hanya terletak pada nilai permintaan yang harus dipenuhi merupakan total nilai permintaan pada dua periode di masa depan. Berikut merupakan gambar permodelan ketiga dengan menggunakan program LINGO 16.0:

$$
\begin{aligned}
& \text { IVar: } \\
& \text { SETS: } \\
& \text { M1 } \\
& \text {, }
\end{aligned}
$$

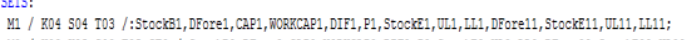

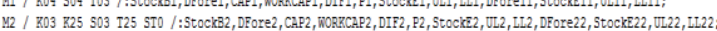

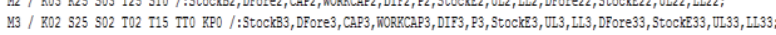
ENDSETS

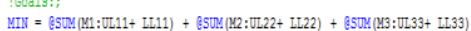

ITime and Hachine constraints;

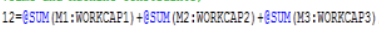

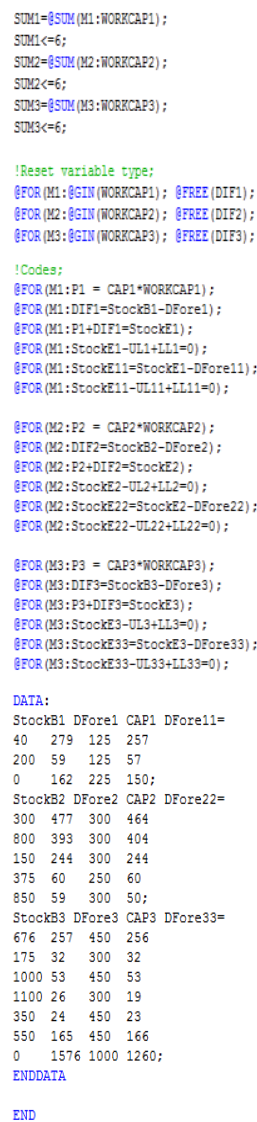

Gambar 3 Model Ketiga Periode 23

\subsection{Hasil dan Analisis Model Perbaikan}

Kedua model akan menghasilkan jumlah produksi dari setiap produk berdasarkan prinsip goal programming. Jumlah produksi tersebut akan dikurangi dengan data permintaan nyata untuk mendapatkan jumlah persediaan akhir pada setiap periode. Berikut merupakan tabel perbandingan persediaan model kedua, model ketiga, dan rencana UKM XYZ: 
Tabel 5. Perbandingan Persediaan Model 2, Model 3 dan UKM XYZ

\begin{tabular}{|c|c|c|c|c|c|c|c|c|c|c|c|c|c|c|c|c|}
\hline Periode & Persediaan & K4 & $\$ 4$ & T3 & $\mathrm{K} 3$ & $\mathrm{~K} 2,5$ & 83 & $\mathrm{~T} 2,5$ & \$T & $\mathrm{K} 2$ & 52.5 & $\$ 2$ & I2 & $\overline{T 1,5}$ & $\overline{\mathrm{TT}}$ & \\
\hline \multirow[t]{3}{*}{23} & UKKNXYZ & 490 & 250 & 225 & 1550 & 800 & 450 & 375 & 850 & 676 & 175 & 1000 & 1100 & 350 & 475 & \\
\hline & Model 2 & 490 & 250 & 225 & 650 & 800 & 450 & 375 & 850 & 676 & 475 & 1000 & 1100 & 350 & 475 & 2 \\
\hline & Model 3 & 490 & 125 & 450 & 650 & 800 & 450 & 375 & 850 & 676 & 175 & 1000 & 1100 & 350 & 475 & 3 \\
\hline \multirow[t]{3}{*}{24} & UKNXYZ & 215 & 750 & 150 & 850 & 550 & 2050 & 375 & 850 & 376 & 175 & 1000 & 1100 & 350 & 1175 & \\
\hline & Model 2 & 465 & 625 & 375 & 250 & 850 & 550 & 875 & 850 & 376 & 775 & 1000 & 1100 & 350 & 275 & 2 \\
\hline & Model 3 & 340 & 750 & 375 & 250 & 550 & 550 & 1375 & 850 & 376 & 175 & 1000 & 1100 & 350 & 275 & 3 \\
\hline \multirow[t]{3}{*}{25} & UKNMXYZ & 135 & 1125 & 750 & 600 & 2200 & 2050 & 375 & 180 & 176 & 175 & 1000 & 1100 & 350 & 1105 & \\
\hline & Model 2 & 885 & 750 & 525 & 900 & 700 & 850 & 875 & 180 & 626 & 775 & 1000 & 1100 & 350 & 655 & 2 \\
\hline & Model 3 & 510 & 1250 & 300 & 900 & 700 & 550 & 1625 & 180 & 626 & 175 & 1000 & 1100 & 350 & 205 & 3 \\
\hline \multirow[t]{3}{*}{26} & UKNMXY2 & 735 & 1125 & 450 & 1300 & 1400 & 1750 & 300 & 680 & 626 & 10 & 1000 & 1000 & 350 & 1105 & $\therefore$ \\
\hline & Model 2 & 1110 & 1000 & 450 & 700 & 500 & 850 & 1050 & 680 & 176 & 610 & 1000 & 1000 & 800 & 655 & \\
\hline & Model 3 & 360 & 2000 & 0 & 400 & 200 & 250 & 2550 & 680 & 176 & 10 & 1000 & 1000 & 350 & 655 & 1 \\
\hline \multirow[t]{3}{*}{27} & $\mathrm{UKN} / \mathrm{XYZ}$ & 810 & 1125 & 1575 & 850 & 1075 & 1750 & 300 & 655 & 1001 & 610 & 1000 & 1000 & 350 & 930 & \\
\hline & Model 2 & 1310 & 1250 & 900 & 550 & 775 & 850 & 1050 & 655 & 551 & 610 & 1000 & 1000 & 800 & 480 & 1 \\
\hline & Model 3 & 685 & 2000 & 225 & 550 & 775 & 250 & 2550 & 655 & 551 & 310 & 1000 & 1000 & 350 & 480 & 1 \\
\hline \multirow[t]{3}{*}{28} & UKKMXYZ & 1360 & 1125 & 1425 & 1050 & 975 & 1450 & 300 & 425 & 701 & 460 & 800 & 1000 & 350 & 900 & 1 \\
\hline & Model 2 & 1610 & 1500 & 750 & 450 & 975 & 550 & 1050 & 725 & 251 & 760 & 800 & 1000 & 800 & 450 & i \\
\hline & Model 3 & 610 & 2625 & 75 & 150 & 975 & 250 & 3050 & 425 & 251 & 160 & 800 & 1000 & 350 & 450 & \\
\hline
\end{tabular}

Hasil persediaan akhir model kedua dan model ketiga tidak memiliki nilai negatif. Hal ini menunjukkan bahwa kedua model perbaikan berhasil memenuhi permintaan sesungguhnya. Selanjutnya akan dihitung nilai pengendapan persediaan dari setiap rencana. Berikut merupakan tabel perbandingannya:

Tabel 6 Perbandingan Nilai Pengendapan Persediaan Model 2, Model 3, dan rencana UKM XYZ (Rupiah)

\begin{tabular}{|c|c|c|c|c|c|c|c|}
\hline Peniole & 23 & 24 & 25 & 26 & 27 & 28 & Rata-rata \\
\hline UKKLIXIZ & 245.588 .775 & 26.243 .775 & 33.955 .025 & 34.207 .275 & 40.809 .150 & 41.267 .900 & 33.506 .983 \\
\hline Model 2 & 23.563 .775 & 27.023 .775 & 33.828.775 & 33.2460 .025 & 39.670 .400 & 39.644150 & 32.828 .650 \\
\hline Model 3 & 24.366.275 & 27828.775 & 34.205 .025 & 33.051 .025 & 39.612 .900 & 40.161 .650 & 33.203 .42 \\
\hline Selish Modele 2 & 9950.000 & .780 .000 & 131.250 & 961.250 & 1.1988 .750 & 1.623 .750 & 678.333 \\
\hline Selish Model 3 & 192.500 & .1580000 & .250 .000 & 1.156 .250 & 1.1996 .250 & 1.106 .250 & 303.942 \\
\hline
\end{tabular}

Hasil perbandingan nilai pengendapan persediaan menunjukkan bahwa kedua model memiliki nilai pengendapan rata-rata lebih sedikit daripada rencana UKM XYZ. Model kedua memiliki nilai pengendapan rata-rata $\mathrm{Rp}$ 678.333,00 lebih sedikit dari rencana UKM XYZ, sedangkan model ketiga memiliki nilai pengendapan rata-rata Rp 303.542,00 lebih sedikit dari rencana UKM XYZ.

\section{Kesimpulan dan Saran}

Peramalan permintaan dapat dilakukan dengan menggunakan tiga metode peramalan deret waktu yang berbeda. Setiap produk dapat menggunakan peramalan yang berbeda dengan produk lainnya. Model pertama tidak dapat memenuhi permintaan sesungguhnya dan memiliki nilai pengendapan persediaan yang lebih tinggi dari rencana UKM XYZ. Model pertama tidak lebih baik dari rencana UKM XYZ, maka dibuat perbaikan dari model tersebut.

Model kedua menggunakan pembobotan kuadrat pada fungsi minimasi defiasi positif persediaan akhir. Model ketiga menggunakan nilai permintaan berupa total dari permintaan pada dua periode di masa depan. Kedua model perbaikan dapat memenuhi permintaan sesungguhnya. Hal ini dapat dilihat dari jumlah persediaan akhir dari setiap periode yang bernilai positif. Model kedua memiliki nilai pengendapan persediaan rata-rata $\mathrm{Rp}$ 678.333,00 lebih sedikit dari rencana UKM XYZ. Model ketiga memiliki nilai pengendapan persediaan rata-rata sebesar $\mathrm{Rp}$ 303.542,00 lebih sedikit dari rencana UKM XYZ. Dapat disimpulkan bahwa model kedua dengan pembobotan kuadrat dapat menjadi solusi terbaik untuk usulan perencanaan produksi UKM XYZ.

Diharapkan penelitian selanjutnya dapat menggunakan data permintaan yang lebih lengkap agar peramalan permintaan memiliki hasil dengan nilai MAD yang lebih kecil. Peneliti selanjutnya juga dapat melakukan perbaikan model dengan cara yang lain agar dapat menemukan hasil yang lebih baik.

\section{Daftar Pustaka}

[1] A. Sven, Inventory Control. $2^{\text {nd }} e d$, New York: Springer Science + Business Media, LCC. 2006.

[2] S.H. Frederick dan J.L. Gerald, Introduction to Operations Research. $7^{\text {th }}$ ed, Boston: McGraw-Hill, 2001.

[3] R. Cristobal, Handbook of Critical Issues in Goal Programming, New York, Pergamon Press. 1991.

[4] S.R. Roberta dan W.T. Bernard, Operations Management: Creating Value Along the Supply Chain. $7^{\text {th }}$ ed, United Kingdom, John Wiley \& Sons, 2011.

[5] T.T. Nick, Demand forecasting for inventory control, Switzerland, Springer International Publishing AG, 2015.

[6] W. Donald, Inventory Control and Management. $2^{\text {nd }} e d$, United Kingdom: John Wiley \& Sons Ltd, 2003. 
[7] C.Y. Livia dan T. Oktiarso, "Penjadwalan Untuk Memininimalkan Total Tardiness Dengan Metode Integer Linear Programming", Jurnal Teknik Industri, Vol. 18, No.02, pp. 127 137, Agustus 2017

[8] W. Anggreini, R.A. Vinarti, R. Tyasnurita dan J. Permatasari, "Production Planning Optimization Using Goal Programming Method in Habibah Busana", Journal of Advanced Management Science, Vol. 3, No. 4, pp. 270-275, December 2015.

[9] Optimization Modelling with Lingo, LINDO Systems Inc, Illinois, 2003.

[10] T.F. Liang dan H.W. Cheng, "Multiobjective aggregate production planning decisions using two-phase fuzzy goal programming method", Journal of Industrial and Management Optimization, Vol. 7, No. 2, pp. 365-383, April 2011.

[11] M. Abolghasemi, E. Beh, G. Tarr, and R. Gerlach, "Demand forecasting in supply chain: The impact of demand volatility in the presence of promotion," Comput. Ind. Eng., vol. 142, no.

February, p. 106380, 2020.

[12] G. Wibisono, S. Rahayuningsih, and $\mathrm{H}$. Santoso, "Analisis Penerapan MRP

Terhadap Perencanaan Dan Pengendalian Persediaan Bahan Baku Pada PT. Latif Di Kediri," JATI UNIK J. Ilm. Tek. dan Manaj. Ind., vol. 1, no. 1, p. 40, 2017.

[13] W. Muchaendepi, C. Mbohwa, T. Hamandishe, and J. Kanyepe, "Inventory management and performance of SMEs in the manufacturing sector of Harare," Procedia Manuf., vol. 33, pp. 454-461, 2019.

[14] Y. Ye and Y. Ge, "A bibliometric analysis of inventory management research based on knowledge mapping," Electron. Libr., vol. 37, no. 1, pp. 127-154, 2019.

[15] H. Jodlbauer and S. Strasser, "Capacity-driven production planning," Comput. Ind., vol. 113, p. 103126 , 2019. 